\title{
Dielectric signatures and evolution of glacier ice
}

\author{
Robert E. GRIMM, ${ }^{1}$ David E. STILLMAN, ${ }^{1}$ Joseph A. MacGREGOR ${ }^{2}$ \\ ${ }^{1}$ Planetary Science Directorate, Southwest Research Institute, Boulder, CO, USA \\ ${ }^{2}$ Institute for Geophysics, The University of Texas at Austin, Austin, TX, USA \\ Correspondence: Robert E. Grimm <grimm@boulder.swri.edu>
}

\begin{abstract}
We analyzed the dielectric spectra $(0.1 \mathrm{~Hz}-1 \mathrm{MHz})$ of 49 firn and ice samples from ice sheets and glaciers to better understand how differing ice formation and evolution affect electrical properties. The dielectric relaxation of ice is well known and its characteristic frequency increases with the concentration of soluble impurities in the ice lattice. We found that meteoric ice and firn generally possess two such relaxations, indicating distinct crystal populations or zonation. Typically, one population is consistent with that of relatively pure ice, and the other is significantly more impure. However, high temperatures (e.g. temperate ice), long residence times (e.g. ancient ice from Mullins Glacier, Antarctica) or anomalously high impurity concentrations favor the development of a single relaxation. These relationships suggest that annealing causes two dielectrically distinct populations to merge into one population. The dielectric response of temperate ice samples indicates increasing purity with increasing depth, suggesting ongoing rejection of impurities from the lattice. Separately, subglacially (lake) frozen samples from the Vostok (Antarctica) 5G ice core possess a single relaxation whose variable characteristic frequency likely reflects the composition of the source water. We conclude that multi-frequency methods are essential to dielectric discrimination between different types of glacier ice.
\end{abstract}

KEYWORDS: glacier chemistry, ice core, ice dynamics, recrystallization

\section{INTRODUCTION}

The electrical properties of glacier ice have been investigated over many orders of magnitude in frequency to help interpret its physical chemistry (e.g. Wolff and others, 1997; Stillman and others, 2013a), density and fabric (e.g. Fujita and others, 2000), the nature of polar ice sheets (e.g. Dowdeswell and Evans, 2004; Eisen and others, 2006; MacGregor and others, 2015) and paleoclimate (e.g. Taylor and others, 1993; Wolff, 2000; WAIS Divide Project Members, 2013). Ice cores are analyzed electrically using several logging methods, most commonly the near-d.c. electrical conductivity measurement (ECM; Hammer, 1980) and high-frequency (up to $300 \mathrm{kHz}$ ) dielectric profiling (DEP; Moore and Paren, 1987; Wilhelms and others, 1998). These tools are optimized for rapid, continuous logging of ice cores. However, a broadband spectrum is required to characterize dielectric dispersion in a material (e.g. Barsukov and Macdonald, 2005). Specifically, measurements distributed from $1 \mathrm{~Hz}$ to $100 \mathrm{kHz}$ are necessary to resolve the dielectric relaxations present in ice, and to separate them from d.c. conductivity. Although some progress has been made in multi-frequency core profiling (e.g. Sugiyama and others, 2000), only laboratory measurements of individual ice samples have provided the dense frequency sampling necessary for robust characterization of the dielectric properties of glacier ice (e.g. Fitzgerald and Paren, 1975; Maeno, 1978; Stillman and others, 2013a). In contrast, measurements $\gg 100 \mathrm{kHz}$ respond only to the sum of d.c. and dielectric conductivity.

This study is motivated by new broadband measurements of polar and temperate glaciers, reported herein, that show both similarities to and differences with ice-sheet spectra. These relationships suggest general features of dielectric spectra that track the formation and evolution of all glacier ice. We first review the fundamentals of dielectric spectroscopy and the salient properties of earlier observations as they relate to diagnostic dielectric signatures of different types of glacier ice, setting aside detailed implications for physical chemistry that we have considered previously (Grimm and others, 2008; Stillman and others, 2010, $2013 a, b)$. We distinguish here between meteoric and accreted ice in polar ice sheets and polar and temperate glaciers, and we differentiate firn from ice for all sources. We evaluate these properties in terms of the formation and evolution of ice masses. We conclude by discussing the value of these dielectric signatures for interpreting several types of measurements, including dielectric spectroscopy of individual ice-core samples, electrical logs of full cores, and geoelectrical measurements in boreholes and soundings from the surface.

\section{BACKGROUND}

Materials respond to time-varying electric fields by a combination of storage and dissipation of energy, which can be represented by a single, frequency-dependent complex number. Here we focus on complex permittivity $\varepsilon^{*}=\varepsilon^{\prime}-$ $\varepsilon^{\prime \prime}(j=\sqrt{-1})$. Other formulations are possible (e.g. complex resistivity or conductivity). The real permittivity $\varepsilon^{\prime}$ determines energy storage (capacitance), and the imaginary permittivity $\varepsilon^{\prime \prime}$ determines energy dissipation (resistance). In principle, one can be predicted from the other using the KramersKronig relations and assuming infinite bandwidth, but, in practice, measuring both gives greater robustness to fitting of bandwidth-limited spectra with multiple constituents.

Polarizability arises from specific charges, mobilities and length scales. It often follows a dispersion called a dielectric relaxation that is due to the frequency-dependent ability of 
charges to move within an applied electric field. The relaxation frequency $f_{\mathrm{r}}$ is the frequency at which charges move over nearly their maximum possible extent during a single applied cycle. A useful description of a dielectric relaxation is the Cole-Cole model (Cole and Cole, 1941). In general, we fit dielectric spectra to a sum of Cole-Cole relaxations plus a static (d.c.) conductivity:

$$
\varepsilon^{*}=\varepsilon_{\infty}+\sum_{i} \frac{\Delta \varepsilon_{i}}{1+\left(j \omega \tau_{i}\right)^{1-\alpha_{i}}}-\frac{j \sigma_{\mathrm{DC}}}{\varepsilon_{0} \omega}
$$

where $\Delta \varepsilon_{i}, \tau_{i}$ and $\alpha_{i}$ are the dielectric susceptibility, relaxation time $\left(1 / 2 \pi f_{\mathrm{r}}\right)$ and Cole-Cole distribution parameter, respectively, for the ith dielectric relaxation, $\omega$ is the angular frequency, $\varepsilon_{\infty}$ is the high-frequency-limit permittivity, $\sigma_{\mathrm{DC}}$ is the d.c. conductivity and $\varepsilon_{0}$ is the permittivity of the vacuum. The parameter $\alpha$ increases with the broadening of the distribution of length scales of charge motion. For a Debye relaxation (Debye, 1929), with a single such length scale, $\alpha=0$. Dielectric relaxations are distinguished by an inflection in $\varepsilon^{\prime}$ and a peak in $\varepsilon^{\prime \prime}$. The distinct appearance of the latter feature simplifies identification and Cole-Cole fitting.

The real part of the conductivity will also approach a high-frequency asymptote $\sigma_{\infty}$ for a Debye relaxation (at any frequency, $\sigma=\varepsilon \omega$ ), but in the general case of $\alpha>0$ there is a continued positive slope. For this reason, we report highfrequency conductivity $\sigma_{\mathrm{HF}}$ at $300 \mathrm{kHz}$ when discussing this quantity.

Between $-40^{\circ} \mathrm{C}$ and $-20^{\circ} \mathrm{C}$, ice relaxation frequencies are typically $>100 \mathrm{~Hz}$ and $<1 \mathrm{kHz}$, so this range in $f_{\mathrm{r}}$ can lead to significant dispersion between $\sim 1 \mathrm{~Hz}$ and $\sim 100 \mathrm{kHz}$. At radio frequencies $(>1 \mathrm{MHz})$, the asymptotic conductivity due to ice relaxation can be inferred, but the ice dispersion itself is not resolved. Furthermore, the close agreement of the $-20^{\circ} \mathrm{C}$ dielectric constant at $1 \mathrm{MHz}(3.20 \pm 0.02$ : Fujita and others, 2000) and the dielectric constant at $10 \mathrm{MHz}-$ $1.5 \mathrm{GHz}$ (3.18 \pm 0.01 : Bohleber and others, 2012) implies that dispersion is minimal and therefore there are no significant undiscovered dielectric relaxations of any kind across this band.

Both polarizability and conductivity in ice are due to protonic charge defects: lattice sites where hydrogen atoms are configured improperly with respect to adjacent $\mathrm{H}_{2} \mathrm{O}$ molecules (Petrenko and Whitworth, 1999). Ice contains a fixed density of intrinsic protonic defects, and extrinsic defects are generated by certain ions (impurities) that are soluble in the ice lattice (e.g. Camplin and others, 1978). In practice, even the purest laboratory-grown ice contains a small proportion of extrinsic defects that are electrically detectable (Kawada, 1978). Dielectric relaxations are generally close to but distinct from the ideal Debye form. MacGregor and others (2015) demonstrated that the effect of non-Debye behavior on conductivity was critical to understanding the relationship between radar attenuation and temperature within the Greenland ice sheet.

For meteoric ice, the dominant soluble impurities are $\mathrm{H}^{+}$ from volcanic acids, $\mathrm{Cl}^{-}$from sea salt and $\mathrm{NH}_{4}{ }^{+}$from biomass burning (Wolff and others, 1997). Jaccard (1959) described the relationships between defect and electrical properties in single-crystal ice, which we refer to hereafter as Jaccard theory (see Appendix). Stillman and others (2013a) showed that the complex permittivity from d.c. to $1 \mathrm{MHz}$ of meteoric polar ice can be fully explained by lattice-soluble impurities using Jaccard theory. Grain boundaries act as resistors that impede d.c. conduction, instead of providing interconnected conductive pathways as previously hypothesized (Wolff and Paren, 1984; Kulessa, 2007). Stillman and others (2013a) also found that in situ 'd.c.' geoelectrical soundings of ice sheets actually better match laboratory-measured trends in $\sigma_{\infty}$, therefore those earlier field measurements are unreliable. The true bulk d.c. conductivity is much lower than those field data, which invalidates earlier models explaining differences between temperate and polar ice that were based on perceived fundamental differences in their d.c. conductivities (Glen and others, 1977; Reynolds and Paren, 1980).

The lattice impurity concentration in polycrystalline ice depends not only on the available sources, but also on the mode of formation. The partition coefficient $k$ from liquid to the ice lattice is small for slowly frozen laboratory ice $\left(\sim 10^{-3}\right.$; Gross and others, 1977; Grimm and others, 2008), because ice formed in this way very efficiently ejects impurities to the grain boundaries. In contrast, $k=0.3-0.8$ for meteoric icesheet samples (Stillman and others, 2013a). These high partition coefficients were derived by comparing Jaccard theory to an empirical relationship between $\sigma_{\mathrm{HF}}$ and bulk impurity concentrations (Wolff and others, 1997; Appendix). Therefore impurity numbers in ice sheets are comparable between the lattice (where low volumetric concentrations are difficult to observe directly) and the much smaller grain boundaries (where higher concentrations can be detected using microscopic imaging (e.g. Mulvaney and others, 1988)). We hypothesize that this behavior results from faster nucleation compared to laboratory freezing and consequent incomplete impurity ejection (Stillman and others, 2013a). This difference in $k$ explains why Fitzgerald and Paren (1975) could not reproduce the electrical properties of a glacier ice sample that they melted and refroze. Weak partitioning from liquid also explains why ice in permafrost is nearly electrically pure (Grimm and Stillman, 2015), i.e. it has few extrinsic defects.

\section{SAMPLES AND METHODS Ice-core samples}

We include all 26 Antarctic and Greenland samples measured by Stillman and others (2013a), who focused on conduction mechanisms in meteoric polar ice. We include new measurements from the Vostok (Antarctica) 5G ice core that include both types of accreted ice found within that core (Jouzel and others, 1999; De Angelis and others, 2004). We supplement these ice-sheet samples with two laboratory dielectric spectra from the earlier literature: the first is a deep sample from the 1968 Byrd Station (Antarctica) ice core (Paren and Glen, 1978) and the second is a firn sample taken from the Palmer Land plateau, Antarctic Peninsula (Reynolds, 1985). We complete our survey of glacier ice with samples from two alpine glaciers: Upper Fremont Glacier, Wyoming, USA, and Mullins Glacier, Beacon Valley, Antarctica. Upper Fremont Glacier is a typical temperate mountain glacier whose high elevation and accumulation rate have proven useful for paleoclimate studies of the past several centuries (Schuster and others, 2000). Mullins Glacier is a cold-based, debris-covered glacier $\sim 8 \mathrm{~km}$ long; isotopic measurements of the overlying till suggest a maximum age $\sim 8 \mathrm{Ma}$ (Marchant and others, 2007). The terminus of this glacier, and a buried relict of Taylor Glacier that abuts it (Sugden and others, 1995), may be the oldest ice on Earth. Table 1 summarizes the origins, 
Table 1. Key characteristics of ice samples evaluated in this study

\begin{tabular}{|c|c|c|c|c|}
\hline \multirow[t]{2}{*}{$\begin{array}{l}\text { Ice core; coordinates; present mean } \\
\text { annual surface temperature; speed }\end{array}$} & Depth & Age & \multirow[t]{2}{*}{$\begin{array}{c}\text { Number of } \\
\text { dielectric relaxations }\end{array}$} & \multirow[t]{2}{*}{ Notes } \\
\hline & $\mathrm{m}$ & ka* & & \\
\hline \multirow{8}{*}{ Vostok $5 \mathrm{G} ; 78.47^{\circ} \mathrm{S}, 106.84^{\circ} \mathrm{E} ;-54^{\circ} \mathrm{C} ; \sim 2 \mathrm{ma}^{-1}$} & 429 & $23^{\mathrm{a}}$ & 2 & Meteoric, high impurities \\
\hline & 2044 & 148 & 2 & Meteoric, high dust \\
\hline & 3478 & $\mathrm{n} / \mathrm{a}$ & 2 & Meteoric \\
\hline & 3552 & $\mathrm{n} / \mathrm{a}$ & 1 & Groundwater-accreted \\
\hline & 3565 & $\mathrm{n} / \mathrm{a}$ & 1 & Groundwater-accreted \\
\hline & 3576 & $\mathrm{n} / \mathrm{a}$ & 1 & Groundwater-accreted \\
\hline & 3608 & $\mathrm{n} / \mathrm{a}$ & 1 & Lake-accreted \\
\hline & 3610 & $\mathrm{n} / \mathrm{a}$ & 1 & Lake-accreted \\
\hline \multirow[t]{4}{*}{ South Pole; $90^{\circ} \mathrm{S} ;-52^{\circ} \mathrm{C} ; \sim 8 \mathrm{~m} \mathrm{a}^{-1}$} & 51 & $0.7^{\mathrm{b}}$ & 2 & Firn \\
\hline & 70 & 1.0 & 2 & Firn, high $\left[\mathrm{H}^{+}\right]$ \\
\hline & 89 & $\sim 1.2$ & 2 & Firn, high $\left[\mathrm{SO}_{4}{ }^{2-}\right]$ \\
\hline & 92 & $\sim 1.3$ & 2 & Firn, high $\left[\mathrm{NH}_{4}^{+}\right]$ \\
\hline \multirow[t]{3}{*}{ Taylor Dome; $77.80^{\circ} \mathrm{S}, 158.72^{\circ} \mathrm{E} ;<-40^{\circ} \mathrm{C} ; \sim 2 \mathrm{ma}^{-1}$} & 102 & $1.5^{\mathrm{c}}$ & 2 & \\
\hline & 375 & 16 & 2 & High impurities \\
\hline & 544 & 197 & 2 & \\
\hline \multirow[t]{6}{*}{ GISP2; $72.58^{\circ} \mathrm{N}, 38.46^{\circ} \mathrm{W} ;-31.5^{\circ} \mathrm{C} ; \sim 2 \mathrm{ma}^{-1}$} & 505 & $2.2^{\mathrm{d}}$ & 2 & Holocene \\
\hline & 1404 & 8.3 & 2 & $\operatorname{High}\left[\mathrm{NH}_{4}^{+}\right]$ \\
\hline & 1406 & 8.4 & 2 & Very high $\left[\mathrm{NH}_{4}{ }^{+}\right]$ \\
\hline & 1710 & 13 & 2 & \\
\hline & 1792 & 15 & 2 & \\
\hline & 2550 & 66 & 1 & High $\left[\mathrm{SO}_{4}\right]^{2-}$ \\
\hline \multirow[t]{4}{*}{ WAIS Divide; $79.47^{\circ} \mathrm{S}, 112.09^{\circ} \mathrm{W} ;-31^{\circ} \mathrm{C} ; \sim 4 \mathrm{ma}^{-1}$} & 117 & $0.4^{\mathrm{e}}$ & 2 & \\
\hline & 210 & 0.8 & 2 & \\
\hline & 447 & 1.8 & 2 & \\
\hline & 575 & 2.3 & 2 & \\
\hline Byrd Station; $80.02^{\circ} \mathrm{S}, 119.53^{\circ} \mathrm{W} ; \sim-30^{\circ} \mathrm{C} ; \sim 7 \mathrm{~m} \mathrm{a}^{-1}$ & 1424 & $24^{f}$ & 2 & $\begin{array}{c}\text { From dielectric spectra measured by } \\
\text { Paren and Glen (1978) }\end{array}$ \\
\hline \multirow{5}{*}{ Newall Glacier; $77.58^{\circ} \mathrm{S}, 162.50^{\circ} \mathrm{E} ;-29^{\circ} \mathrm{C} ; \sim 2 \mathrm{ma}^{-1}$} & 55 & $1.5^{\mathrm{g}}$ & 2 & \\
\hline & 80 & 3 & 2 & \\
\hline & 102 & 4 & 2 & \\
\hline & 120 & 6 & 2 & \\
\hline & 133 & 7 & 1 & $\mathrm{High}\left[\mathrm{SO}_{4}{ }^{2-}\right]$ \\
\hline \multirow[t]{5}{*}{ Siple Dome; $81.65^{\circ} \mathrm{S}, 149.00^{\circ} \mathrm{W} ;-25^{\circ} \mathrm{C} ; \sim 5 \mathrm{~m} \mathrm{a}^{-1}$} & 55 & $0.3^{\mathrm{h}}$ & 2 & \\
\hline & 185 & 1.7 & 1 & High $\left[\mathrm{H}^{+}\right]$ \\
\hline & 559 & $\sim 9$ & 2 & \\
\hline & 719 & $\sim 17$ & 2 & \\
\hline & 1004 & $\mathrm{n} / \mathrm{a}$ & 2 & \\
\hline $\begin{array}{l}\text { Mullins Glacier } \mathrm{MCl}-04-002 ; 77.91^{\circ} \mathrm{S}, 160.59^{\circ} \mathrm{E} ; \\
-23^{\circ} \mathrm{C} ; \ll 1 \mathrm{~m} \mathrm{a}^{-1}\end{array}$ & 8.6 & $<10^{\mathrm{j}}$ & 2 & $\begin{array}{l}\text { Adjacent to accumulation zone. Clear ice. } \\
\text { All Mullins samples contain inclusions. }\end{array}$ \\
\hline $\begin{array}{l}\text { Mullins Glacier MCl-04-009; } 77.89^{\circ} \mathrm{S}, 160.57^{\circ} \mathrm{E} ; \\
-23^{\circ} \mathrm{C} ; \ll 1 \mathrm{~m} \mathrm{a}^{-1}\end{array}$ & 1.3 & $\sim 300$ & 1 & $\begin{array}{l}1.9 \mathrm{~km} \text { from accumulation zone. Clear } \\
\text { ice. }\end{array}$ \\
\hline \multirow[t]{6}{*}{$\begin{array}{l}\text { Mullins Glacier MCl-09-003; } 77.88^{\circ} \mathrm{S}, 160.54^{\circ} \mathrm{E} \\
-23^{\circ} \mathrm{C} ; \ll 1 \mathrm{~m} \mathrm{a}^{-1}\end{array}$} & 0.7 & $\begin{array}{c}\sim 640 \\
\text { No vertical } \\
\text { discrimination }\end{array}$ & 1 & $\begin{array}{l}3.3 \mathrm{~km} \text { from accumulation zone. Similar } \\
\text { in } 2 \text { adjacent shallow borings. Clear ice }\end{array}$ \\
\hline & 6.0 & & 1 & Discolored ice \\
\hline & 15.3 & & 2 & Clear ice \\
\hline & 16.2 & & 1 & Discolored ice \\
\hline & 16.5 & & 1 & Clear ice \\
\hline & 31.3 & & 1 & Clear ice \\
\hline $\begin{array}{l}\text { Palmer Land Plateau; } 70.02^{\circ} \mathrm{S}, 64.48^{\circ} \mathrm{W} ;-21^{\circ} \mathrm{C} \text {; } \\
2 \mathrm{~m} \mathrm{a}^{-1}\end{array}$ & 5.6 & $<50$ years & 1 & $\begin{array}{l}\text { Firn. From dielectric spectra measured by } \\
\text { Reynolds (1985) }\end{array}$ \\
\hline \multirow{4}{*}{$\begin{array}{l}\text { Upper Fremont FRE91-1; } 43.13^{\circ} \mathrm{N}, 109.62^{\circ} \mathrm{W} \text {; } \\
\text { temperate ice; } 1 \mathrm{~m} \mathrm{a}^{-1}\end{array}$} & 4.0 & $1986 \mathrm{CE}^{\mathrm{k}}$ & 1 & Firn \\
\hline & 13.5 & $1975 \mathrm{CE}$ & 2 & Ice \\
\hline & 74.2 & $1900 \mathrm{CE}$ & 1 & Ice \\
\hline & 137.9 & $1760 \mathrm{CE}$ & 1 & Ice \\
\hline
\end{tabular}

*Unless otherwise stated.

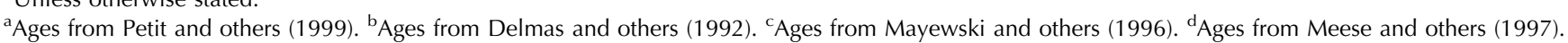
${ }^{\mathrm{e}}$ Ages from WAIS Divide Project Members (2013). ${ }^{\mathrm{f}}$ Ages from Blunier and Brook (2001). ${ }^{\mathrm{P}}$ Ages extrapolated from Mayewski and others (1995). ${ }^{\mathrm{h}} \mathrm{Ages}$ from Brook and others (2005). ${ }^{\mathrm{j} C}$ Cosmogenic ages interpolated from Marchant and others (2007). ${ }^{\mathrm{k}}$ Dates from Schuster and others (2000).

depths, ages and visual characteristics of the ice samples included in this analysis. All samples were obtained from the US National Ice Core Laboratory and were cut there to thicknesses of 7-14 mm. Samples were stored in our laboratory in a humidified freezer at $-40^{\circ} \mathrm{C}$ for a period up to several months before measurement. 


\section{Dielectric measurements}

Samples were measured between two circular electrodes, an upper $55 \mathrm{~mm}$ diameter unguarded electrode and a lower guarded electrode whose diameter $(10-30 \mathrm{~mm})$ depended on the sample diameter (Solartron 12963A sample holder). The grounded guard (third) electrode was sized to match the diameter of the composite lower electrode to the upper electrode. Complex impedance was measured as a function of frequency and temperature using a Solartron 1260A Impedance Analyzer with a 1296A Dielectric Interface. This system is capable of measuring conductivities as low as $10^{-12} \mathrm{~S} \mathrm{~m}^{-1}$ and phases of $0.1 \mathrm{mrad}$. The impedance was converted to complex permittivity using the electrode geometry. Uncertainties estimated from repeat measurements are typically $5 \%$ and $10 \%$ for $\varepsilon^{\prime}$ and $\varepsilon^{\prime \prime}$, respectively. For Mullins Glacier samples, some of which could not be microtomed due to englacial debris, there was no difference in dielectric signature between clear samples that were microtomed, and discolored or dirty samples that were not and that were frozen onto warmed electrodes instead.

Measurements were swept from high to low frequency, from $10^{6}$ to $10^{-1} \mathrm{~Hz}$ (we rarely exploit the system's lower limit of $10^{-3} \mathrm{~Hz}$ due to measurement time). Because measurements are more reproducible during warming and eliminate the possible confounding effects of meta-stable water, we typically cool samples slowly to $-90^{\circ} \mathrm{C}$ and then collect data during slow warming $\left(0.1^{\circ} \mathrm{C} \mathrm{min}{ }^{-1}\right)$, with more than $30 \mathrm{~min}$ stabilization at each $2.5^{\circ} \mathrm{C}$ measurement interval. We observed no discontinuities indicating phase transitions. The large temperature range allows frequencyoverlapping polarization mechanisms to be identified by the temperature dependence (activation energy) of their individual relaxation frequencies.

\section{Modeling of dielectric spectra}

At each temperature, the complex permittivity spectra were modeled as a sum of Cole-Cole relaxations and d.c. conductivity (Eqn (1)). We note that even if a spectral slope remains at low frequency, the d.c. conductivity can still be recovered accurately by this modeling procedure. We fit both $\varepsilon^{\prime}$ and $\varepsilon^{\prime \prime}$ simultaneously; the model root-mean-square (RMS) misfit for both quantities was typically $\sim 1 \%$. 95\% confidence bounds on the Cole-Cole parameters for each relaxation were estimated using changes in goodness of fit $\left(\Delta \chi^{2}\right.$ distributions). The characteristic frequency for each relaxation reflects the total number of defects according to Jaccard theory (see Appendix). Grimm and others (2008) and Stillman and others (2010, 2013a) provide additional details of measurement and fitting procedures.

\section{RESULTS}

Figure 1 shows the dielectric spectra of all samples at approximately $-40^{\circ} \mathrm{C}$, illustrating the range of dielectric behaviors observed in glacier ice. This temperature was the highest measured across all samples (some were measured at higher temperatures, but not uniformly so) and was selected to avoid any potential pre-melting effects. However, we note that this temperature is somewhat lower than those (typically $-20^{\circ} \mathrm{C}$ ) at which full-core profiling methods are collected (e.g. ECM, DEP). Cole-Cole fitting (Table 2) separates the individual dielectric relaxations that combine to produce the observed dielectric spectra, and Figure 2 shows representative examples of these fits. These multiple relaxations include both the polarization of protonic defects in the ice lattice and extraneous electrode polarizations (labeled as 'other' in Fig. 2). F-tests indicate that fitting of multiple relaxations is highly significant $(p<0.01)$ because the normalized reduction in $\chi^{2}$ typically exceeds $95 \%$ and the number of parameters added for each relaxation (3) is small compared to the number of spectral data points $(\sim 50$ complex values).

Figure 3 is an Arrhenius plot of relaxation frequency as a function of temperature, showing that individual relaxations associated with the ice lattice are consistently distinguishable in terms of both their magnitude and temperature dependence. Finally, Figure 4 shows modeled $\sigma_{\mathrm{HF}}$ at $-40^{\circ} \mathrm{C}$ for all samples and for each relaxation. We also use Jaccard theory to infer the concentration of soluble impurities in the lattice from $f_{\mathrm{r}}$ (Appendix). Because we do not have complete bulk chemistry information for all samples, we express the impurity concentration as the apparent concentration of a single species, alternatively $\left[\mathrm{H}^{+}\right]$or $\left[\mathrm{Cl}^{-}\right]$ (Fig. 4b).

A large majority (23/26) of the meteoric ice-sheet samples possess two dielectric relaxations. A third relaxation was resolved in GISP2 (Greenland) $1406 \mathrm{~m}$ that has been discarded for clarity in the analysis here (Stillman and others, 2013a). Two relaxations require two distinct impurity populations. Often, one of these relaxations has the characteristics of nearly pure ice. The remainder (3/26) of the meteoric ice-sheet samples have a single relaxation. All of these samples are associated with high bulk impurity concentrations, although other samples with high impurity concentrations may still retain two relaxations. Vostok samples possess three distinct behaviors: two relaxations associated with meteoric ice (the three shallowest samples); a single relaxation indicating high impurities from the impurity-rich type 1 accreted ice; and a single relaxation indicating relatively high purity in the deeper lake-accreted ice (type 2; the two deepest samples).

Due to the presence of insoluble inclusions, the first type (1) of Vostok accretion ice is believed to have frozen onto either the grounded base of the East Antarctic ice sheet upstream of Vostok Subglacial Lake itself or within a shallow bay upstream of the main lake body (Bell and others, 2002; De Angelis and others, 2004; MacGregor and others, 2009). Its relatively high $\sigma_{\mathrm{HF}}$ values are equivalent to apparent $\left[\mathrm{Cl}^{-}\right] \sim 10^{-4} \mathrm{M}$, or a source-water concentration $\sim 0.1 \mathrm{M}$ assuming $k=10^{-3}$. This result is consistent with $\mathrm{Cl}^{-}$as the major impurity in this ice (De Angelis and others, 2004) and a brackish source. At the other extreme, the lake-accreted ice (type 2; 3608 and $3610 \mathrm{~m}$ ) is nearly pure, as to be expected from a very low partition coefficient and a large freshwater body (Kapitsa and others, 1996).

The sample from Mullins Glacier nearest the accumulation zone has two relaxations, and, as with the ice sheets, one indicates a population of nearly pure ice. The other Mullins Glacier samples have a single relaxation, with the notable exception of a sample near the end of the active portion of the glacier whose two relaxations indicate two distinct high-impurity populations. Many of the Mullins Glacier samples have among the highest HF conductivities and apparent soluble lattice impurities in our study. Upper Fremont Glacier samples mostly have single relaxations, and its deepest sample ( $>90 \%$ of the local ice thickness) indicates a near-pure ice lattice. Firn samples (6 total) have 


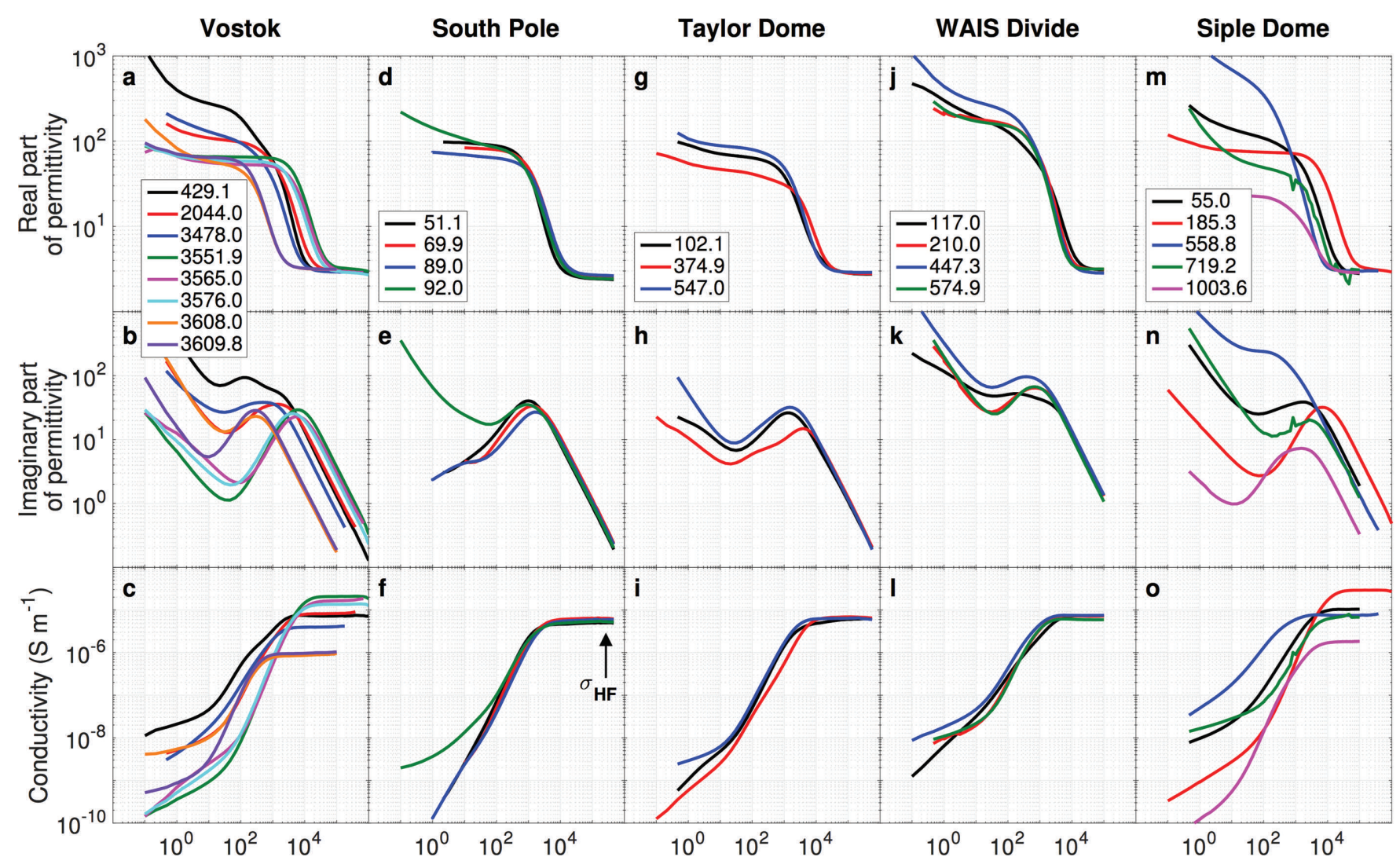

Frequency $(\mathrm{Hz})$

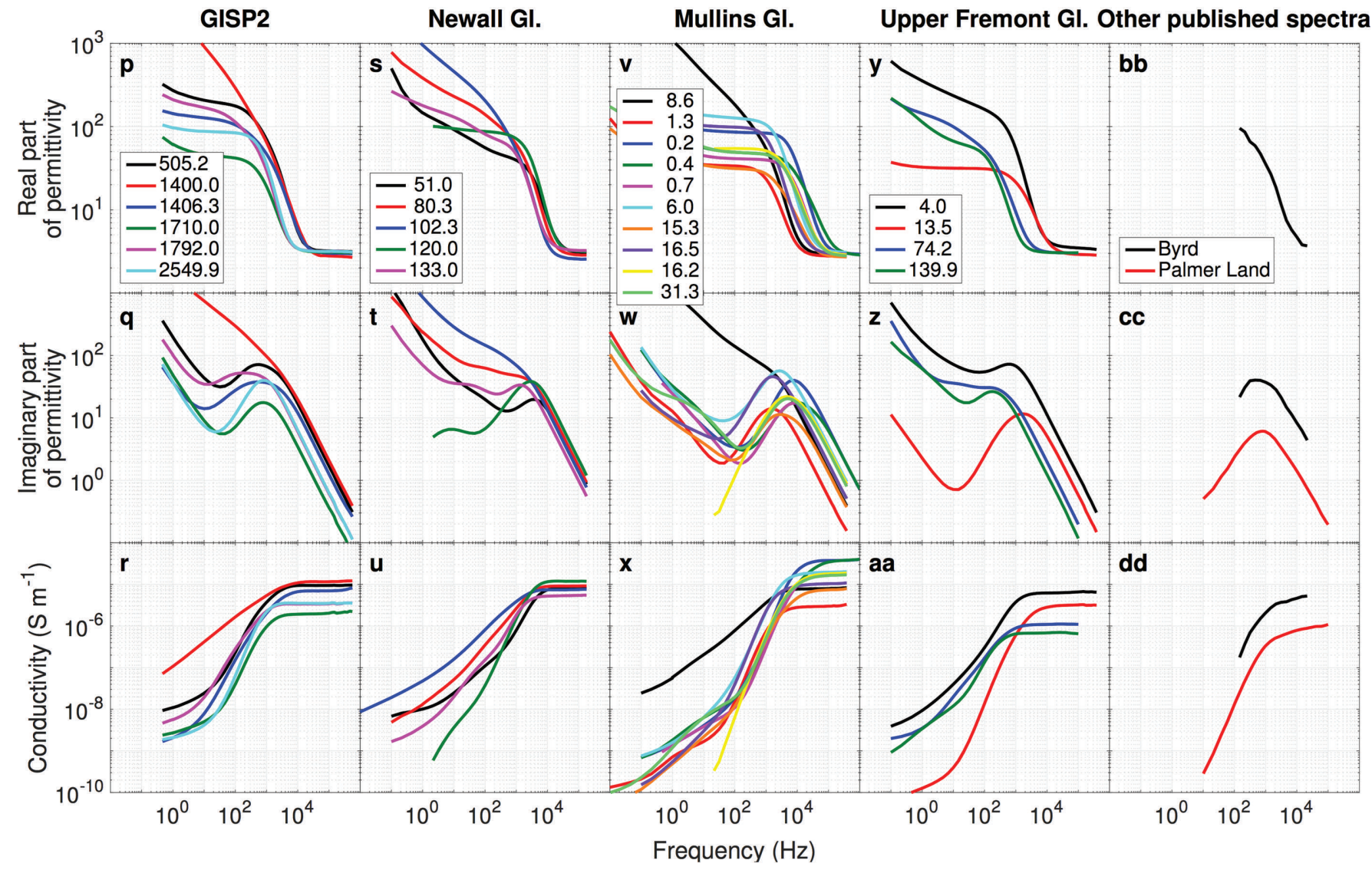

Fig. 1. Dielectric spectra of all samples at $-40^{\circ} \mathrm{C}$. Each column represents a different ice core, and the individual curves represent each sample (legend gives depth $(\mathrm{m})$ ). The top two rows for each sample are the free-space normalized real $\varepsilon^{\prime}$ and imaginary $\varepsilon^{\prime \prime}$ parts of the complex relative permittivity (i.e. the real and imaginary dielectric constants). The bottom row shows real conductivity $\sigma$. Dielectric relaxations can be identified as peaks in $\varepsilon^{\prime \prime}$ and inflections in $\varepsilon^{\prime}$. Note high-frequency (HF) conductivity at $300 \mathrm{kHz}\left(\sigma_{\mathrm{HF}}\right)$ is highlighted for South Pole samples. Byrd and Palmer Land samples shown in lower right column were digitized from measurements by Paren and Glen (1978) and Reynolds (1985), respectively. 
Table 2. Cole-Cole parameters

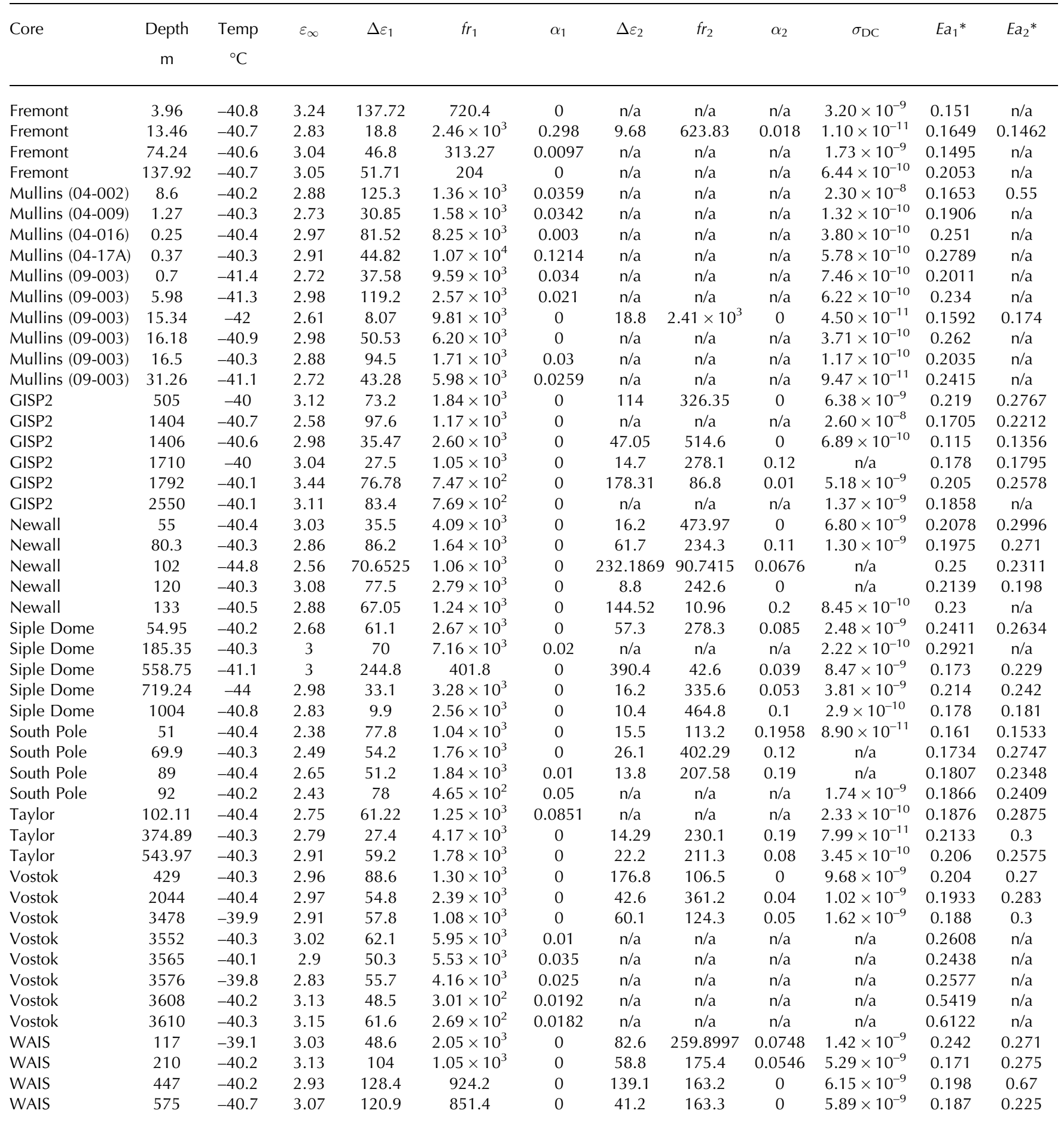

Note: n/a: Cole-Cole parameters not applicable (only one ice relaxation) or d.c. conductivity too small to measure.

*Activation energies (Ea) are specifically for relaxation frequencies.

either one (2/6) or two (4/6) relaxations and thus are similar to densified ice in terms of Cole-Cole behavior.

\section{DISCUSSION}

\section{Primary features of dielectric signatures}

Both the characteristic relaxation frequencies and their associated activation energies observed in many of our samples fall within ranges expected for protonic point defects in ice (Fig. 3). Therefore, we ascribe dual relaxations to the ice lattice, rather than attributing one to another mechanism such as a Maxwell-Wagner interfacial polarization. Low-frequency $\left(<1 \mathrm{~Hz}\right.$ at $-40^{\circ} \mathrm{C}$; Fig. 2) relaxations in our measurements, outside the ice-lattice range, can be attributed to electrode polarization. Additional polarizations have been reported in shaved glacier ice (Paren and Glen, 1978) and artificially dispersed ice (Boned and others, 1979). These polarizations also lie outside the protonicdefect domain, and we suggest they are interfacial effects. For ice grown from liquid in the laboratory, we have never observed two or more relaxations that can be attributed to the lattice (cf. von Hippel and others, 1971, et seq.). At very 


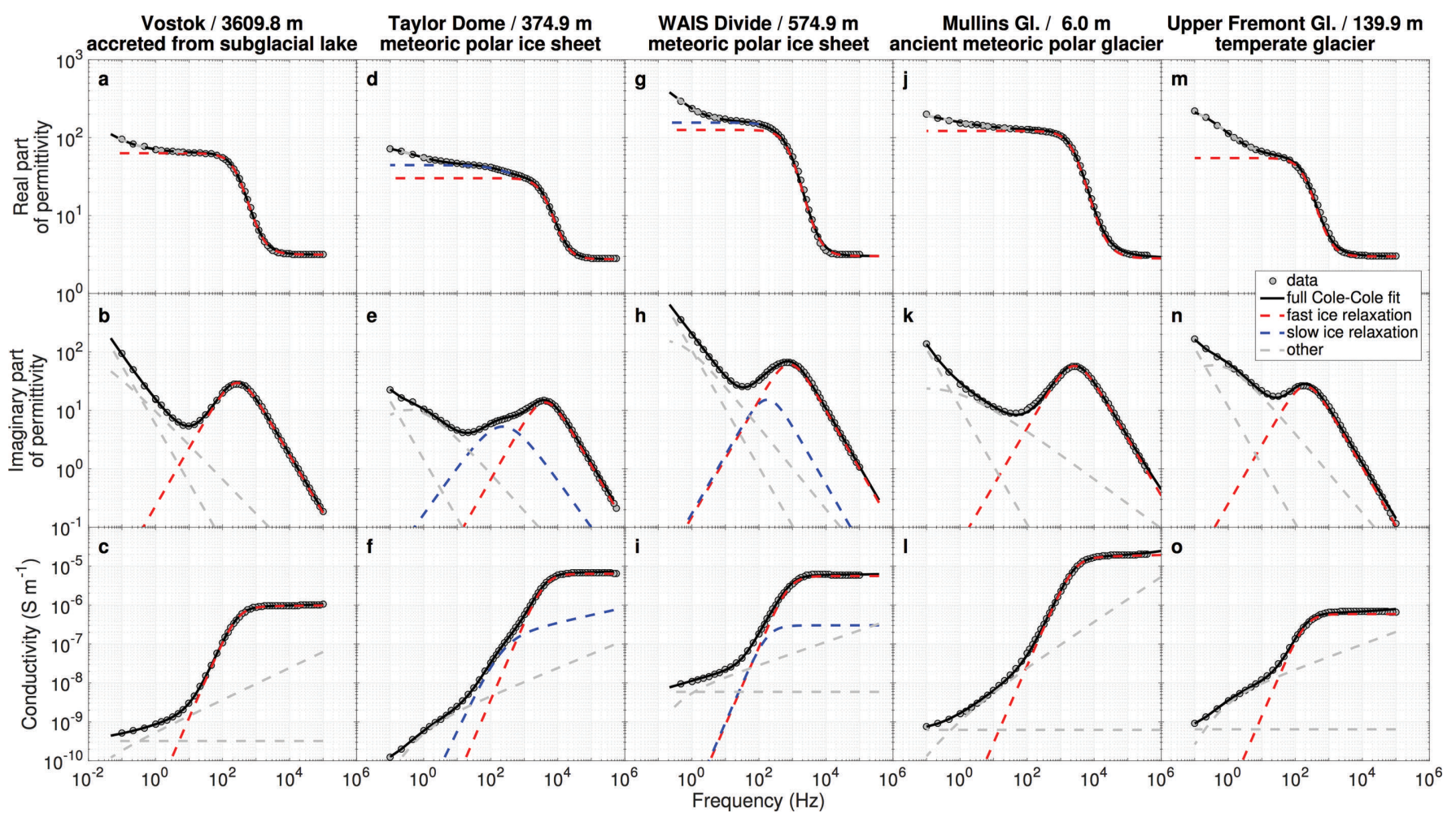

Fig. 2. Cole-Cole fits at $-40^{\circ} \mathrm{C}$ for selected samples. Dielectric relaxations associated with the ice lattice are shown in red and blue. The d.c. conductivity and electrode polarizations are shown in grey (labeled as 'other'). RMS misfits are $\sim 1 \%$ and F-tests indicate that multiple relaxations significantly improve the fits.

high salt concentrations in the parent liquid $(>1 \mathrm{M})$, the dielectric relaxation of salt hydrate can appear (Grimm and others, 2008), but this complication is not relevant to lowimpurity glacier ice.

The presence of two relaxations, therefore, appears to be unique to meteoric ice and indicates two separate ices with different impurity concentrations. If these impurities were well mixed, they would yield a single relaxation whose frequency was related to the mean impurity concentration, but perhaps with a broader distribution of length scales of charge motion (larger $\alpha$ ). These two impurity populations could represent two distinct crystal populations, bimodal zonation within crystals, or a large number of separate, smaller bimodal electrical domains within a crystal. The last possibility is especially speculative, but could involve enhanced concentrations of defects near dislocation cores necessary to overcome the proton-disorder barrier, or screening charge clouds that surround dislocation dangling bonds (Petrenko and Whitworth, 1999).

Impurity partitioning into the ice lattice could be affected by the nature of impurity deposition on the subaerial surface (Stillman and others, 2013a), i.e. whether it occurs through aerosol deposition ('dry') or whether impurities are incorporated within snowflakes ('wet'). It is not clear how wet vs dry impurity deposition could generate distinct grain populations. On the other hand, scanning-electron and X-ray imaging of ice (Mulvaney and others, 1988; Barnes and others, 2003) revealed that $\mathrm{NaCl}$ and other salts are present as inclusions within ice grains. The threshold concentration for impurity detection with these methods $\left(\sim 10^{-3} \mathrm{M}\right)$ greatly exceeds bulk concentrations $\left(\sim 10^{-6} \mathrm{M}\right)$. Therefore, the lattice around the inclusions may be significantly enhanced in soluble ions as sensed dielectrically, forming multiple 'cores' of impurities surrounded by a 'mantle' of relatively pure ice.
Alternatively, lattice impurities may be pushed toward grain boundaries immediately upon recrystallization from snow to firn. This arrangement is supported by microscopic

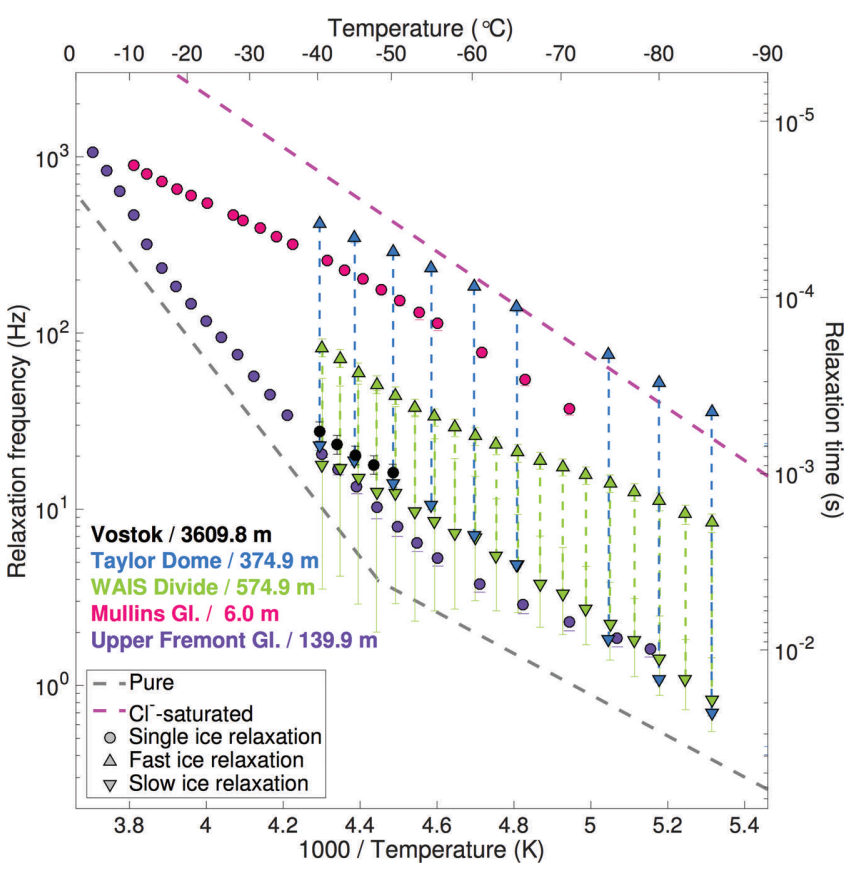

Fig. 3. Arrhenius plot of reciprocal temperature vs relaxation frequency for the samples shown in Figure 2. The relaxation frequencies of ice crystal populations are higher than those of laboratory-frozen pure ice (Kawada, 1978), whose change in slope is due to laboratory purity limit. These relaxations are also generally below $\mathrm{Cl}^{-}$-saturation limit (Grimm and others, 2008), except where $\mathrm{NH}_{4}{ }^{+}$-enhanced $\mathrm{Cl}^{-}$ partitioning is present (Stillman and others, 2013b). 


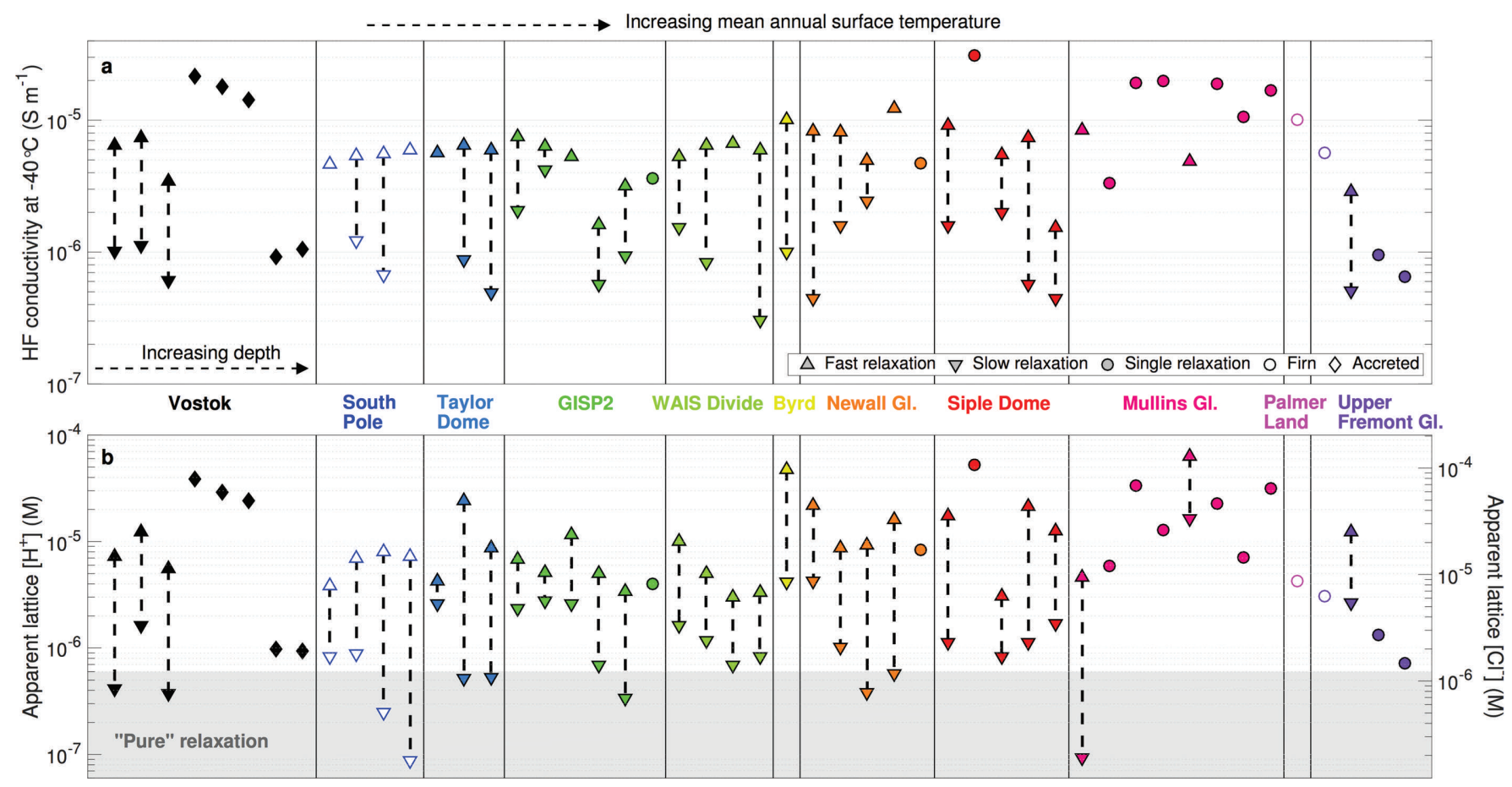

Fig. 4. (a) HF conductivity of all samples at $-40^{\circ} \mathrm{C}$. (b) Apparent lattice impurity concentrations, derived assuming either [ $\left.\mathrm{H}^{+}\right]$(left axis) or $\left[\mathrm{Cl}^{-}\right]$(right axis) was the only soluble impurity (Appendix). $\mathrm{HF}$ conductivities for two relaxations sometimes merge at $-40^{\circ} \mathrm{C}$, but fitting time constants at multiple temperatures (Fig. 3) assures that dual relaxations are resolved. Firn (open symbols) is distinguished from glacier ice (filled symbols). Two relaxations are common, even in firn, indicating that impurities are bimodally partitioned into crystal lattices during formation. Single relaxations in Vostok accreted ice are the result of direct freezing from liquid. Single relaxations of temperate ice trend toward increasing purity with depth, indicating that near-complete impurity ejection from the lattice is the end result of annealing.

imaging (Barnes and others, 2003) that identified coating of grain boundaries with salts and acids. Again, the high detection threshold for those imaging methods suggests that a zone of dielectrically impure ice may be adjacent to such grain-boundary coatings. In this configuration, a single purer core of each grain is surrounded by an impure mantle.

The lower bound for the dimension of electrical domains is the characteristic polarization displacement of protonicpoint defects, which we estimate to be $\sim 1 \mu \mathrm{m}$ (see Appendix). If zonation existed on a smaller scale, charges would be unable to move through a sinusoidal cycle at the relaxation frequency and the relaxation spectrum would be distorted. Because this dimension is a very small fraction of the typical grain diameter, the core/mantle zonation hypothesis posed above is tractable. However, dislocation widths may be as small as one unit cell, so associated point-defect zones might be tens of unit cells wide, i.e. $\sim 0.01 \mu \mathrm{m}$. Hence, we conclude that individual dislocations are too small to be the sources of the bimodal dielectric relaxations observed in glacier ice. However, dislocations are known to interact over longer distances (Duval and others, 2010), so an effect of dislocations over larger scales cannot be ruled out.

Single-relaxation ice represents the minority of our samples, but it is not rare and occurs in all ice types we examined. Three of the meteoric ice-sheet samples (Siple Dome (Antarctica) 185 m; GISP2 2250 m; Newall Glacier (Antarctica) $133 \mathrm{~m}$ ) possess single relaxations and were among the most impure samples for those respective cores that we sampled (Stillman and others, 2013a). Single relaxations dominate the Vostok accreted ice (5/5) and both alpine glaciers (10/12). The Mullins Glacier samples have
$\sigma_{\mathrm{HF}}$ values that are higher than average, which presumably reflects the higher concentration of lattice-soluble impurities that accompanies the source-zone debris input. However, there is no clear relationship between dielectric signature and macroscopic englacial debris concentration or even ice discoloration in Mullins Glacier samples (Table 1). Because discolored ice is found at many levels in the cores, it is likely an effect of variable dust loading and not basal entrainment (cf. Holdsworth and Bull, 1970). Further, the concentration of englacial debris even in discolored samples of Mullins Glacier must be small, because no ice-silicate interfacial polarizations are evident (Olhoeft, 1977; Stillman and others, 2010; Grimm and Stillman, 2015).

\section{Evolution of dielectric signatures}

There are several key observations that shed light on the dielectric evolution of glacier ice. (1) Two relaxations are widespread in ice and firn. In GISP2, two relaxations are preserved through normal recrystallization/grain growth. In many ice sheets, two relaxations are still evident at the greatest ages sampled, up to a few hundred thousand years. (2) Conversely, the three ice-sheet samples that have only one relaxation are relatively impure, or are the deepest/ oldest in that core. Mullins Glacier samples, dominated by single relaxations (6/8), are both impure and old (at least several hundred thousand years in the analyzed core; note that the putative $8 \mathrm{Ma}$ ice is at the glacier terminus). (3) In temperate Upper Fremont Glacier, 3/4 of the samples have only one relaxation, and the three single relaxations trend toward lower $\sigma_{\mathrm{HF}}$ with increasing depth. We now consider the significance of these observations for understanding the evolution of soluble impurities within glacier ice. Table 3 
Table 3. Summary of types of dielectric signatures and associated glacier ice types. Meteoric ice evolves from upper left to lower right

\begin{tabular}{|c|c|c|c|c|}
\hline Dielectric signature* & Polar ice sheet & $\begin{array}{l}\text { Polar } \\
\text { alpine glacier }\end{array}$ & $\begin{array}{l}\text { Temperate } \\
\text { alpine glacier }\end{array}$ & $\begin{array}{l}\text { Subglacially } \\
\text { frozen ice }\end{array}$ \\
\hline $\begin{array}{l}\text { Ice formation } 2 \text { dielectric relaxations } \\
\text { ( } 1 \text { may indicate near-pure ice) }\end{array}$ & $\begin{array}{l}\text { GISP2, Newall Glacier, Siple Dome, } \\
\text { South Pole, Vostok and WAIS }\end{array}$ & Mullins Glacier & Not observed & Not observed \\
\hline $\begin{array}{l}\text { Partial annealing } \\
1 \text { dielectric relaxation (impure ice) }\end{array}$ & $\begin{array}{c}\text { All of the above, plus Taylor Dome, } \\
\text { and Byrd and Palmer Land }\end{array}$ & Mullins Glacier & Upper Fremont Glacier & $\begin{array}{l}\text { Vostok accreted } \\
\text { ice type } 1\end{array}$ \\
\hline $\begin{array}{l}\text { Complete annealing } \\
1 \text { dielectric relaxation (near-pure ice) }\end{array}$ & Not observed & Not observed & Upper Fremont Glacier & $\begin{array}{l}\text { Vostok accreted } \\
\text { ice type } 2\end{array}$ \\
\hline
\end{tabular}

*`Pure' defined as apparent $\left[\mathrm{H}^{+}\right]<0.6 \mu \mathrm{M}$ inferred from Jaccard theory.

summarizes the relationships between observations and our proposed evolution.

We hypothesize that annealing, probably grain internal recovery, can explain part or all of these observations. We adopt the metallurgical definition of annealing (Doherty and others, 1997) as the sum of processes that cause high-angle grain-boundary migration (recrystallization) and those internal processes removing dislocations and point defects (recovery). Because firn can also have two relaxations, we assume that all meteoric ice initially possesses (or is at least capable of possessing) two relaxations (dielectric populations). As ice ages, annealing causes these two populations to merge into one, and this process is strongly temperaturedependent. Anomalously high concentrations of latticesoluble impurities accelerate annealing and hence the population-merging process. Annealing further purifies ice by progressively removing lattice defects.

In terms of the specific hypotheses introduced above for the nature of the dielectric domains, the annealing hypothesis does not favor two initially distinct crystal populations, because merging during normal recrystallization would then immediately combine the two dielectric relaxations into one. However, multiple impure cores formed around aerosol nuclei could be preserved while grain boundaries are changing, or impure mantles could continuously remerge on migrating grain boundaries.

Preservation of two dielectric relaxations through the process of normal grain recrystallization implies further that the subsequent process that merges dielectric domains is grain internal recovery. Specifically, grain growth in GISP2 is complete in <5 ka (Gow and others, 1997; Meese and others, 1997), yet two dielectric relaxations are evident for at least $20 \mathrm{ka}$. Indeed, several of our samples have ages exceeding $100 \mathrm{ka}$ and still show two dielectric relaxations (Vostok $2044 \mathrm{~m}$, Taylor Dome (Antarctica) $544 \mathrm{~m}$ and Mullins Glacier MCl-09-003 15.3 m; Table 1).

Figure 4 shows that there is no clear relationship between dielectric signature and mean annual surface temperature (a simple proxy for depositional conditions) and only hints at such a relationship with depth (a simple proxy for time). One of these three samples is $\sim 150 \mathrm{ka}$ old (Vostok $2044 \mathrm{~m}$ ), implying that over this period at low in situ temperatures $\left(<-35^{\circ} \mathrm{C}\right)$, it has not yet experienced sufficient annealing to merge the impurity populations. Our deepest GISP2 sample $(2550 \mathrm{~m})$ had only a single relaxation and is only $67 \mathrm{ka}$ old, but it experienced generally higher temperatures. We note that typical surface speeds of the Antarctic ice sheet are $\sim 10 \mathrm{ma}^{-1}$ (Rignot and others, 2011) and all of the ice-core samples we measured were drawn from average- to slower-flowing locations. Samples from fast-moving ice $\left(>100 \mathrm{ma}^{-1}\right)$ would help further constrain the relative importance of cumulative strain upon dielectric evolution.

These slow rates for merging dielectric populations imply lower diffusion coefficients $D$ or higher activation energies $E_{\mathrm{a}}$ than those derived for recrystallization. For example, $E_{\mathrm{a}}$ for volume self-diffusion $\left(62 \mathrm{~kJ} \mathrm{~mol}^{-1}\right.$; Petrenko and Whitworth, $1999)$ is larger than that for recrystallization $\left(42 \mathrm{~kJ} \mathrm{~mol}^{-1}\right.$; Cuffey and Paterson, 2010). However, even when accounting for these possible differences, $D$ must be at least two orders of magnitude smaller than the volume self-diffusion coefficient (Petrenko and Whitworth, 1999). Assuming $t>t_{\mathrm{d}} \sim r^{2} / \pi^{2} D$, where $t$ is the observed greatest age with two relaxations, $t_{\mathrm{d}}$ is a characteristic diffusion time and $r$ is the grain radius $(\sim 3 \mathrm{~mm})$, we find that $D$ must be less than $\sim 10^{-18}-10^{-17} \mathrm{~m}^{2} \mathrm{~s}^{-1}$ at $-20^{\circ} \mathrm{C}$ to account for the long recovery times implied by our observations of the Siple Dome, Byrd, GISP2, Taylor Dome and Vostok ice cores. We hypothesize that the Mullins Glacier sample from the $\sim 600$ ka core (MCl-09-003) that still possesses two relaxations was further delayed in annealing due to insolubleimpurity pinning or an anomalously low temperature.

The common pattern of two relaxations with variable degrees of apparent purity is consistent with a stochastic climatic overprint associated with variable impurity deposition and the well-recognized dielectric stratigraphy of ice cores recorded by ECM and DEP. This overprint can occasionally produce an anomalous dielectric signature (i.e. a single relaxation), despite similar physical conditions and history (temperature and age), as appears to have occurred for at least three of our samples (Siple Dome 185 m; GISP2 2250 m; Newall Glacier 133 m). Based on the dielectric signatures of these samples, we further hypothesize that unusually high concentrations of lattice-soluble impurities accelerate annealing.

In contrast, ice with the oldest double relaxation observed in temperate Upper Fremont Glacier was formed only about a decade before coring, suggesting that $D$ is only a few times smaller than expected for volume diffusion. Reynolds and Paren (1980) invoked faster recrystallization rates in temperate glaciers, as compared to polar glaciers, to explain the lower d.c. conductivity of the former. However, their hypothesis has been invalidated by the discovery that 'd.c.' polar field measurements were instead generally sensitive to the HF response of ice (Stillman and others, 2013a). Nevertheless, annealing remains central to our present hypothesis as to why temperate glaciers rapidly evolve dielectrically into a single-relaxation material. 
Ultimately, soluble impurities may be completely ejected from the lattice to the intergranular surfaces, where they no longer have a dielectric relaxation because they are in intergranular liquid or have become enclathrated. In Upper Fremont Glacier, the three samples showing single relaxations are increasingly pure with depth. Meltwater flushing cannot directly affect lattice-incorporated impurities, so either this ordering is coincidence $(17 \%$ three-way permutation probability) or lattice impurity concentrations are decreasing with increasing depth or time. The time to evolve toward nearly pure ice appears to be a few centuries, also consistent with volume diffusion. The lower temperatures, higher activation energies, lower diffusion coefficients or higher proportion of insoluble impurities appropriate to non-temperate ice inhibit this progression.

Single relaxations with high $\mathrm{Cl}^{-}$concentrations are also found in Vostok accreted ice type 1. Although the single relaxation is readily distinguished as a primary difference between accreted or laboratory-frozen ice compared to meteoric ice, the apparent lack of annealing toward a pure lattice is unexpected. Larger diffusion times would be associated with the larger $(\sim 20 \mathrm{~cm})$ crystals of Vostok accreted ice type 1; therefore, if impurity rejection is controlled in the same way as Upper Fremont Glacier, the upper limit to the age of this accreted ice is $\sim 1000$ years. The high purity of accreted ice type 2 likely arises directly from partitioning from Vostok Subglacial Lake.

\section{CONCLUSIONS}

We surveyed the broadband dielectric behavior $(0.1 \mathrm{~Hz}-$ $1 \mathrm{MHz}$ ) of 49 samples of naturally formed glacier ice (including two from previous studies), produced by multiple formation mechanisms, containing varying impurity concentrations and subjected to differing temperature histories. This large sample size enabled a first qualitative classification and analysis of the variety of broadband dielectric signatures that are observed in such ice. A synthesis of these measurements reveals the following: (1) Meteoric polar ice generally possesses two dielectric relaxations representing a bimodal zonation of impurity domains. These zones likely either surround insoluble impurities within the lattice or form coatings near grain boundaries. (2) Higher temperatures, longer time periods and higher impurity concentrations all tend to result in a single-relaxation dielectric signature, presumably reflecting greater cumulative annealing, specifically grain internal recovery. Not all samples obey these relationships, further indicating the importance of spatio-temporally variable impurity deposition in modulating the dielectric signature of meteoric ice. (3) Subglacially accreted (lake-frozen) ice possesses only one relaxation, whose degree of purity likely reflects the accretion rate and composition of the source water.

These common dielectric signatures underlie the timevariable impurity deposition that produces the variable bulk signals typically observed in ECM and DEP logs. A key source of uncertainty in our conclusions that warrants further investigation is a quantitative evaluation of the relationship between annealing rates and dielectric properties (e.g. HF conductivity). In particular, the slower diffusion implied by the dielectric evolution compared to volume diffusion requires further investigation. We suggest that focused application of other tools applied to study ice (e.g. electron microscopy, diffraction topography, measurements at radio- to infrared frequencies) may reveal the origin of distinct impurity domains.

This study further demonstrates the utility of broadband $(<1 \mathrm{~Hz}$ to $>100 \mathrm{kHz})$ laboratory measurements of complex permittivity for understanding the origin and evolution of glacier ice using cut core samples. Multi-frequency profiling of full cores would provide spatially complete core data. We recommend that the minimum frequency be reduced to $<1 \mathrm{~Hz}$ to allow robust Cole-Cole fitting and separation of the constituent conduction and polarization mechanisms. Such a change would, however, decrease the speed of data acquisition to $\sim 1 \mathrm{~mm} \mathrm{~s}^{-1}$. We also recommend that such full-core profiling be performed at the lowest temperature possible, well below the typical $-20^{\circ} \mathrm{C}$, as lower temperatures enhance separation and modeling of multiple ice relaxations.

\section{ACKNOWLEDGEMENTS}

This work was funded by NASA's Planetary Geology and Geophysics program (NNX14AN30G) and by Southwest Research Institute (Internal Research Grant R8422). We acknowledge Mark Twickler, Geoffrey Hargreaves and Richard Nunn for access to and preparation of ice samples at the US National Ice Core Laboratory. We are grateful to Doug Kowalewski for discussions about Mullins Glacier and for initiating our sample requests. We thank Steve Arcone and an anonymous reviewer for constructive comments.

\section{REFERENCES}

Barnes PRF, Wolff EW, Mallard DC and Mader HM (2003) SEM studies of the morphology and chemistry of polar ice. Microsc. Res. Tech., 62(1), 62-69

Barsukov E and Macdonald JR (2005) Impedance spectroscopy: theory, experiment, and applications. Wiley, Hoboken, NJ

Bell RE, Studinger M, Tikku AA, Clarke GKC, Gutner MM and Meertens C (2002) Origin and fate of Lake Vostok water frozen to the base of the East Antarctic ice sheet. Nature, 416(6878), 307-310

Blunier T and Brook EJ (2001) Timing of millennial-scale climate change in Antarctica and Greenland during the last glacial period. Science, 291, 109-112

Bohleber P, Wagner N and Eisen O (2012) Permittivity of ice at radio frequencies: Part I. Coaxial transmission line cell. Cold Reg. Sci. Technol., 82, 56-67 (doi: 10.1016/j.coldregions.2012. 05.011)

Boned C, Lagourette B and Clausse M (1979) Dielectric behaviour of ice microcrystals: a study versus temperature. J. Glaciol., 22(86), 145-154

Brook EJ and 8 others (2005) Timing of millennial-scale climate change at Siple Dome, West Antarctica, during the last glacial period. Quat. Sci. Rev., 24, 1333-1343 (doi: 10.1016/ j.quascirev.2005.02.002)

Camplin GC, Glen JW and Paren JG (1978) Theoretical models for interpreting the electrical behaviour of HF-doped ice. J. Glaciol., 21(85), 123-141

Carslaw HS and Jaeger JC (1959) Conduction of heat in solids. Oxford University Press, Oxford

Cole KS and Cole RH (1941) Dispersion and adsorption in dielectrics. I: Alternating current characteristics. J. Chem. Phys. 9(4), 341-352

Cuffey KM and Paterson WSB (2010) The physics of glaciers, 4th edn. Elsevier, Amsterdam

De Angelis, M, Petit JR, Savarino J, Souchez R and Thiemens MH (2004) Contributions of an ancient evaporitic-type reservoir to 
subglacial Lake Vostok chemistry. Earth Planet. Sci. Lett., 222, 751-765 (doi: 10.1016/j.epsl.2004.03.023)

Debye PJW (1929) Polar molecules. Chemical Catalog Company, New York

Delmas RJ, Kirchner S, Palais JM and Petit JR (1992) 1000 years of explosive volcanism recorded at the South Pole. Tellus B, 44, 335-350

Doherty RD and 9 others (1997) Current issues in recrystallization: a review. Mat. Sci. Eng., A238, 219-274

Dowdeswell JA and Evans S (2004) Investigations of the form and flow of ice sheets and glaciers using radio-echo sounding. Rep. Progr. Phys., 67, 1821-1861 (doi: 1088/0034-4885/ 67/10/R03)

Duval P, Montagnat M, Grennerat F, Weiss J, Meyssonnier J and Philip A (2010) Creep and plasticity of glacier ice: a material science perspective. J. Glaciol., 56(200), 1059-1068 (doi: 10.3189/002214311796406185)

Eisen O, Wilhelms F, Steinhage D and Schwander J (2006) Improved method to determine radio-echo sounding reflector depths from ice-core profiles of permittivity and conductivity. J. Glaciol., 52(177), 299-310 (doi: 10.3189/172756506781828674)

Fitzgerald WJ and Paren JG (1975) The dielectric properties of Antarctic ice. J. Glaciol. 15(73), 39-59

Fujita S, Matsuoka T, Ishida T, Matsuoka K and Mae S (2000) A summary of the complex dielectric permittivity of ice in the megahertz range and its applications for radar sounding of polar ice sheets. In Hondoh T ed. Physics of ice core records. Hokkaido University Press, Sapporo, 185-212

Glen JW, Homer DR and Paren JG (1977) Water at grain boundaries: its role in the purification of temperate glacier ice. IAHS Publ. 118 (Symposium at Grenoble 1975 - Isotopes and Impurities in Snow and Ice), 263-271

Gow AJ and 6 others (1997) Physical and structural properties of the Greenland Ice Sheet Project 2 ice core: a review. J. Geophys. Res., 102(C12), 26559-26575

Grimm, RE and Stillman DE (2015) Field test of detection and characterization of subsurface ice using broadband spectral induced polarization. Permafrost Periglac. Process., 26, 28-38 (doi: 10.1002/ppp.1833)

Grimm RE, Stillman DE, Dec SF and Bullock MW (2008) Lowfrequency electrical properties of polycrystalline saline ice and salt hydrates. J. Phys. Chem. B, 112(48), 15382-15390 (doi: 10.1021/jp8055366)

Gross GW, Wong PM and Humes K (1977) Concentration dependent solute redistribution at the ice-water phase boundary. III. Spontaneous convection. Chloride solutions. J. Chem. Phys., 67(11), 5264-5274

Hammer CU (1980) Acidity of polar ice cores in relation to absolute dating, past volcanism, and radio-echoes. J. Glaciol., 25(93), 359-372

Holdsworth G and Bull C (1970) The flow law of cold ice: investigations on Meserve Glacier, Antarctica. IAHS Publ. 86 (Symposium at Hanover 1968 - Antarctic Glaciological Exploration (ISAGE)), 204-216

Jaccard C (1959) Thermodynamics of irreversible processes applied to ice. Phys. Kondens. Mater., 3, 99-118

Jouzel J and 9 others (1999) More than 200 meters of lake ice above subglacial Lake Vostok. Science, 286, 2138-2141

Kapitsa AP, Ridley JK, Robin GdeQ, Siegert MJ and Zotikov IA (1996) A large deep freshwater lake beneath the ice of the central East Antarctic. Nature, 381(6584)

Kawada S (1978) Dielectric anisotropy in ice Ih. J. Phys. Soc. Jpn, 44(6), 1881-1886

Kulessa B (2007) A critical review of the low-frequency electrical properties of ice sheets and glaciers. J. Environ. Eng. Geophys. 12(1), 23-36

MacGregor JA, Matsuoka K and Studinger M (2009) Radar detection of accreted ice over Lake Vostok, Antarctica. Earth Planet. Sci. Lett., 282, 222-233 (doi: 10.1016/j.epsl.2009. 03.018)
MacGregor JA and 11 others (2015) Radar attenuation and temperature within the Greenland Ice Sheet. J. Geophys. Res. Earth Surf., 120 (doi: 10.1002/2014JF003418)

Maeno N (1978) The electrical behaviours of Antarctic ice drilled at Mizuho Station, East Antarctica. Mem. Natl Inst. Polar Res., 10, 77-94

Marchant DR and 8 others (2007) Establishing a chronology for the world's oldest glacier ice. USGS Open-File Rep. 2007-1047, 054

Mayewski, PA and 11 others (1995) An ice-core-based, late Holocene history for the Transantarctic Mountains, Antarctica. Antarct. Res. Ser. 67, 33-45

Mayewski PA and 13 others (1996) Climate change during the last deglaciation in Antarctica. Science, 272, 1636-1638

Meese DA and 8 others (1997) The Greenland Ice Sheet Project 2 depth-age scale: methods and results. J. Geophys. Res., 102(C2), 26 411-26 423

Moore JC and Paren JG (1987) A new technique for dielectric logging of Antarctic ice cores. J. Phys. [Paris], 48(C1), 155-160

Mulvaney R, Wolff EW and Oates K (1988) Sulphuric acid at grain boundaries in Antarctic ice. Nature, 331(6153), 247-249

Olhoeft GR (1977) Electrical properties of natural clay permafrost. Can. J. Earth Sci., 14, 16-24

Paren JG and Glen JW (1978) Electrical behaviour of finely divided ice. J. Glaciol., 21(85), 173-191

Petit JR and 18 others (1999) Climate and atmospheric history of the past 420,000 years from the Vostok ice core, Antarctica. Nature, 399, 429-436

Petrenko VF and Whitworth RW (1999) Physics of ice. Oxford University Press, Oxford

Reynolds JM and Paren JG (1980) Recrystallisation and the electrical behaviour of glacier ice. Nature, 283(5742), 63-64

Reynolds M (1985) Dielectric behaviour of firn and ice from the Antarctic Peninsula, Antarctica. J. Glaciol., 31(109), 253-262

Rignot E, Mouginot J and Scheuchl B (2011) Ice flow of the Antarctic ice sheet. Science 333(6048), 1427-1430 (doi: 10.1126/science.1208336)

Schuster PF, White DE, Naftz DL and Cecil LD (2000) Chronological refinement of an ice core record at Upper Fremont Glacier in south central North America. J. Geophys. Res., 105, 4657-4666 (doi: 10.1029/1999JD901095)

Stillman DE, Grimm RE and Dec S (2010) Low-frequency electrical properties of ice-silicate mixtures. J. Phys. Chem. B, 114(18), 6065-6073 (doi: 10.1021/jp9070778)

Stillman DE, MacGregor JA and Grimm RE (2013a) The role of acids in electrical conduction through ice. J. Geophys. Res., 118 (doi: 10.1029/2012JF002603)

Stillman DE, MacGregor JA and Grimm RE (2013b) Electrical response of ammonium-rich water ice. Ann. Glaciol., 54(64), 21-26 (doi: 10.3189/2013AoG64A204)

Sugden DE and 6 others (1995) Preservation of Miocene glacier ice in East Antarctica. Nature, 376, 412-414

Sugiyama K and 7 others (2000) Measurement of electrical conductance in ice cores by AC-ECM method. In Hondoh T ed. Physics of ice core records. Hokkaido University Press, Sapporo, 173-184

Taylor KC and 7 others (1993) The 'flickering switch' of late Pleistocene climate change. Nature, 361, 432-436

Von Hippel A, Knoll DB and Westphal WB (1971) Transfer of protons through 'pure' ice $I_{h}$ single crystals. I. Polarization spectra of ice $I_{\mathrm{h}}$. J. Chem. Phys., 54(1), 134-144

WAIS Divide Project Members (2013) Onset of deglacial warming in West Antarctica driven by local orbital forcing. Nature, 500, 440-444 (doi: 10.1038/nature12376)

Wilhelms F, Kipfstuhl J, Miller H, Heinloth K and Firestone J (1998) Precise dielectric profiling of ice cores: a new device with improved guarding and its theory. J. Glaciol., 44(146), 171-174

Wolff EW (2000) Electrical stratigraphy of polar ice cores: principles, methods and findings. In Hondoh T ed. Physics of ice core records. Hokkaido University Press, Sapporo, 155-171 
Wolff EW and Paren JG (1984) A two-phase model of electrical conduction in polar ice sheets. J. Geophys. Res., 89(B11), 9433-9438

Wolff EW, Miners WD, Moore JC and Paren JG (1997) Factors controlling the electrical conductivity of ice from the polar regions - a summary. J. Phys. Chem. B, 101(32), 6090-6094

\section{APPENDIX \\ Jaccard theory and apparent soluble-impurity concentrations}

We use Jaccard theory (Petrenko and Whitworth, 1999) to determine the concentration of lattice defects from the measured dielectric properties (Fig. 4). We express these defect concentrations alternatively as the apparent lattice concentration of $\mathrm{H}^{+}$or $\mathrm{Cl}^{-}$, because these impurities are dominant in naturally formed ice. We denote these concentrations as 'apparent' because either, both, or their combination with $\mathrm{NH}_{4}{ }^{+}$could produce the observed dielectric signature. These concentrations were estimated using a dimensionless constant $G=3$, the mean distance between oxygen ions in the ice lattice $\left(r_{O O}=2.764 \times 10^{-10} \mathrm{~m}\right)$, the mobility of L-defects at $-20^{\circ} \mathrm{C}\left(\mu_{\mathrm{L}}^{-20}=1.5 \times 10^{-8} \mathrm{~m}^{2} \mathrm{~V}^{-1} \mathrm{~s}^{-1}\right)$, the mobility of ionic defects at $-20^{\circ} \mathrm{C}\left(\mu_{+}^{-20}=10^{-9} \mathrm{~m}^{2} \mathrm{~V}^{-1} \mathrm{~s}^{-1}\right)$, the charge of L-defects $\left(e_{\mathrm{L}}=0.38 \mathrm{e}\right.$, where $\mathrm{e}$ is the charge of a proton) and the charge of ionic defects $\left(e_{+}=0.62 e\right)$. The temperature dependence of $\tau$ was analyzed to estimate $\left[\mathrm{Cl}^{-}\right]$ and the activation energy of the mobility. We also assume that a single $\mathrm{Cl}^{-}$ion produces two L-defects, i.e. $n_{\mathrm{L}}=2\left[\mathrm{Cl}^{-}\right]$, while a single $\mathrm{H}^{+}$ion produces a single ionic defect $n_{+}=\left[\mathrm{H}_{+}\right]$. Jaccard theory defines $\sigma$ and $\tau$ as

$$
\begin{gathered}
\sigma_{\mathrm{L}}=n_{\mathrm{L}} \mathrm{e}_{\mathrm{L}} \mu_{\mathrm{L}} \\
\sigma_{+}=n_{+} e_{+} \mu_{+} \\
\frac{1}{\tau}=\varphi\left(\frac{\sigma_{+}}{e_{+}^{2}}+\frac{\sigma_{\mathrm{L}}}{e_{\mathrm{L}}^{2}}\right)
\end{gathered}
$$

where $\varphi=\frac{8 \sqrt{3}}{G} r_{O O} k_{\mathrm{B}} T, k_{\mathrm{B}}$ is the Boltzmann constant and $T$ is temperature. We then assume alternately that the relaxation is due to ionic or L-defects only:

$$
\frac{1}{\tau}=\varphi\left(\frac{\sigma_{+}}{e_{+}^{2}}\right)=\varphi\left(\frac{\sigma_{\mathrm{L}}}{e_{\mathrm{L}}^{2}}\right)
$$

The end-member conductivities in Eqn (A4) can then be translated to end-member (apparent) concentrations first by assuming that $\mathrm{L}$-defects dominate and fitting observed $\tau$ as a function of temperature to find the activation energy of $\mu_{\mathrm{L}}$.

$$
\frac{1}{\tau}=\frac{n_{\mathrm{L}} \mathrm{e}_{\mathrm{L}} \mu_{\mathrm{L}} \phi}{\mathrm{e}_{\mathrm{L}}^{2}}=\frac{2\left[\mathrm{Cl}^{-}\right] \mu_{\mathrm{L}} \phi}{\mathrm{e}_{\mathrm{L}}}
$$

Once the apparent $\left[\mathrm{Cl}^{-}\right]$has been calculated, apparent $\left[\mathrm{H}^{+}\right]$ follows from

$$
\begin{gathered}
\frac{\sigma_{+}}{\mathrm{e}_{+}^{2}}=\frac{\sigma_{\mathrm{L}}}{\mathrm{e}_{\mathrm{L}}^{2}} \\
\frac{n_{+} e_{+} \mu_{+}}{\mathrm{e}_{+}^{2}}=\frac{n_{\mathrm{L}} \mathrm{e}_{\mathrm{L}} \mu_{\mathrm{L}}}{\mathrm{e}_{\mathrm{L}}^{2}} \\
\frac{\left[\mathrm{H}^{+}\right] \mu_{+}}{e_{+}}=\frac{2\left[\mathrm{Cl}^{-}\right] \mu_{\mathrm{L}}}{e_{\mathrm{L}}} \\
\frac{\left[\mathrm{H}^{+}\right]}{\left[\mathrm{Cl}^{-}\right]}=2 \frac{e_{+} \mu_{\mathrm{L}}}{e_{\mathrm{L}} \mu_{+}}=0.49
\end{gathered}
$$

\section{Length scale of charge motion}

We exploit the analogy between flow of heat and charge to determine the characteristic length scale of protonic-defect displacement within the ice lattice in response to an applied electric field. The e-folding time constant $\tau$ is derived from the polarization response to a step change in voltage. Following a step change in temperature to a one-dimensional half-space, the corresponding length scale as a function of time is approximately $\delta=\pi \sqrt{D \tau}$, where $D$ is the diffusion coefficient (Carslaw and Jaeger, 1959). The angular relaxation frequency is the reciprocal of the relaxation time. We take $\tau=8.4 \times 10^{-14} \exp (5000 / T)$ as representative of our samples; this function is logarithmically intermediate between pure and chloride-saturated ice.

We then calculate $D=k_{\mathrm{B}} T \mu_{\mathrm{L}} / \mathrm{e}_{\mathrm{L}}$ (Petrenko and Whitworth, 1999), where the mobility and charge are appropriate to the majority L-defects, which dominate a.c. conduction. Using the values given above for $\mu_{\mathrm{L}}$ and $e_{\mathrm{L}}$, we calculate $\delta=0.5 \mu \mathrm{m}$ at $-20^{\circ} \mathrm{C}$. The activation energy $0.24 \mathrm{eV}$ for L-defects increases $\delta$ only to $0.9 \mu \mathrm{m}$ at $-50^{\circ} \mathrm{C}$. Therefore, the characteristic length scale to which defect charges can be dielectrically displaced is large compared to the lattice spacing $(0.3 \mathrm{~nm})$, but small compared to typical grain sizes $(>1 \mathrm{~mm})$. We note that there are no theoretical limitations to charge movement under a steady (d.c.) applied current, where lattice conductivity is determined by the appropriate balance of defect types (Petrenko and Whitworth, 1999) modulated by grain-boundary resistance (Stillman and others, 2010). 